\title{
Harmful Commercial Marketing and Children's Rights: For a Better Use of EU Powers
}

\author{
Amandine GARDE* (1)
}

The marketing of tobacco, alcohol, unhealthy food and gambling services is harmful to public health, the European economy and sustainability. If the European Union (EU) has embraced the regulation of cross-border marketing for tobacco products for over two decades, it has consistently resisted evidence-driven calls to regulate the marketing of other harmful commodities, preferring instead to rely on ineffective industry pledges. This contribution reflects on why the EU has failed to use its competence to regulate cross-border marketing more systematically to protect health and highlights why the time is ripe to reconsider the issue, before concluding with a possible way forward.

\section{INTRODUCTION}

In February 2020, the WHO-UNICEF-Lancet Commission published a report emphasising the "severe threats" posed to children by "harmful commercial marketing" and called for its regulation, urging the international community to work towards the adoption of an Optional Protocol to the UN Convention on the Rights of the Child (CRC). ${ }^{1}$

Whether such a protocol is likely to be adopted any time soon is not what this contribution proposes to address. However, the growing international recognition that harmful commercial marketing should be envisaged as a major children's rights issue has several implications for the European Union (EU) and its Member States. Therefore, in the context of the development of a new EU Children's Rights Strategy 2021-2024, this article reflects on what such debates entail for the EU. As several contributors have argued in this Special Issue, the EU does need more powers to protect public health effectively; this contribution takes a different angle and argues that the EU should also reflect on how it uses its existing powers to comply with its twin obligation to ensure a high level of public health protection and promote children's rights in all of its policies. If the EU has embraced the regulation of tobacco cross-border marketing for over two decades, it has also resisted evidencedriven calls to regulate the marketing of other harmful commodities, such as

\footnotetext{
* University of Liverpool, UK; email: amandine.garde@liverpool.ac.uk.

1 H Clark et al, “A future for the world's children? A WHO-UNICEF-Lancet Commission” (2020) 395 The Lancet 605.
} 
gambling, alcohol or unhealthy food, ${ }^{2}$ preferring instead to limit its intervention to the promotion of (largely ineffective) industry pledges and the exchange of best practice between Member States of action taken at the national level.

This article discusses the EU's failure to use its competence to regulate crossborder marketing more systematically in order to protect public health at regional level (Section II), before highlighting that the time is ripe to reconsider the issue. The political landscape is changing. Not only is the EU under increasing pressure to do more, but there are also encouraging signs that the current European Commission is prepared to address this issue more effectively than its predecessors (Section III).

\section{The LACK OF A UNIFORM EU APPROACH TO HARMFUL}

\section{COMMERCIAL MARKETING}

If the EU has addressed the marketing of tobacco products, increasing its regional grip on the tobacco industry, it has considered the food, alcohol and gambling industries as partners in the regulation of their marketing practices through a misplaced, dogmatic belief in the virtues of self-regulation. This is especially problematic for children, who are particularly vulnerable consumers ${ }^{3}$ and must be protected against exploitation for commercial gain. ${ }^{4}$

\section{Tobacco}

Over the years, the EU has adopted wide-ranging measures to restrict the marketing of tobacco products to the point that all EU lawyers are familiar with the Court's case law in which the tobacco industry challenged the different measures that the EU adopted to this effect $^{5}$ and led to a "federal experimentation" on both the limits and the exercise of EU powers. ${ }^{6}$ Together, the Tobacco Advertising Directive,${ }^{7}$ the Tobacco Products Directive ${ }^{8}$ and the Audiovisual Media Services Directive (AVMSD) ${ }^{9}$ ban the advertising,

\footnotetext{
2 Unhealthy food is nutritiously poor and high in fat, sugar and salt. It is often highly processed and includes nonalcoholic beverages. The distinction between healthy and unhealthy food is based on nutrition profiling, defined by the World Health Organization as the science of classifying or ranking food according to the composition of its nutrients, in the interests of preventing disease and promoting health: <https://www.who.int/nutrition/topics/profiling/en/ > .

3 For example, Art 5(3) of Directive 2005/29 on business-to-consumer unfair commercial practices explicitly recognises age as a factor of vulnerability that must be considered when assessing the fairness of a commercial practice, OJ 2005 L149/22.

4 S Linn, Consuming Kids: Protecting Our Children from the Onslaught of Marketing and Advertising (New York, Anchor 2004). On the relationship between digital marketing and the right of the child to be free from exploitation, see M Tatlow-Golden and A Garde, "Digital Food Marketing to Children: Exploitation, Surveillance and Rights Violations", Global Food Security (2020, forthcoming).

5 See, in particular, Case C-376/98 Germany v Council and EP [2000] ECR 1-8419; Case C-491/01 British American Tobacco [2002] ECR I-11453; Case C-380/03 Germany v Council and EP (Tobacco Advertising II) [2006] ECR I-11573; and Case C-547/14 Philip Morris ECLI:EU:C:2016:325.

6 A Alemanno and A Garde, "The Emergence of an EU Lifestyle Policy: The Case of Alcohol, Tobacco and Unhealthy Diets" (2013) 50(6) Common Market Law Review 1745. See also V Delhomme, "Between Market Integration and Public Health: The Paradoxical EU Competence to Regulate Tobacco Consumption", Research Paper in Law 01/2018 (College of Europe 2018).

7 Directive 2003/33, OJ 2003 L 152/16.

8 Directive 2014/40, OJ 2014 L 127/1.

9 Directive 2010/13, OJ 2010 L 95/1, as amended by Directive 2018/1808, OJ 2018 L 303/69.
} 
sponsorship and product placement of tobacco products on a broad range of media with a cross-border dimension.

This not to say that the EU has regulated all possible forms of marketing it could have regulated at the regional level using the powers it derives from Article 114 TFEU. In particular, the EU could have decided to impose an EU-wide tobacco plain packaging scheme. However, in the absence of sufficient political will to this effect, the EU has left the initiative to Member States, subject to general EU free movement provisions, without stifling their efforts. ${ }^{10}$ When Philip Morris and other tobacco manufacturers called on the Court of Justice of the European Union (CJEU) to "clarify" the regulatory discretion Member States retained to adopt national laws exceeding the requirements of the Tobacco Products Directive, the Court ruled that the directive was a measure of partial harmonisation that did not harmonise all aspects of tobacco product packaging and that Member States could therefore adopt national measures imposing the plain packaging of tobacco products, ${ }^{11}$ which the UK, France, Ireland, Slovenia, Hungary, Belgium and the Netherlands have now done. ${ }^{12}$

Overall, however, even though there may still be implementation gaps, the regulation of tobacco marketing has been extensive and an integral part of the EU's multifaceted attempts to "denormalise" smoking throughout the EU and implement the World Health Organization (WHO) Framework Convention on Tobacco Control (FCTC) within the constraints imposed by the principle of attributed powers. ${ }^{13}$

\section{Gambling, alcohol and unhealthy food}

At the other end of the spectrum, there is no sector-specific EU legislation in the field of gambling services, whose marketing remains unregulated at the EU level, beyond general consumer protection rules. In 2014, the EU adopted a recommendation laying down principles for the protection of consumers and players of online gambling services and for the prevention of minors from gambling online, ${ }^{14}$ calling on Member States to ensure that commercial communications for online gambling services do not harm

\footnotetext{
10 Art 24(2) of Directive 2014/40.

11 Even though the wording of Art 24(2) does not contain a specific statement to that effect - the Court noted - "such an interpretation is consonant with the objective and general scheme of the directive": Case C-547/14 Philip Morris ECLI:EU:C:2016:325, paras 38 and 73. This means that if a national scheme was challenged under Arts 34-36 TFEU, the CJEU would be likely to rule that plain packaging is a measure of equivalent effect to a quantitative restriction that can be justified on public health grounds under Art 36 TFEU. In this sense, the CJEU has preempted the outcome of challenges based on the free movement provisions regarding the compatibility of national tobacco control measures relating to aspects of the packaging that are not regulated by the Tobacco Products Directive. In so doing, it has maintained the rather broad margin of discretion Member States have under Art 36 TFEU.

12 Similarly, Art 20(5) of Directive 2014/40 regulates the marketing of e-cigarettes. On e-cigarettes, see L Gruszczynski (ed.), The Regulation of E-Cigarettes: International, European and National Challenges (Cheltenham, Edward Elgar 2019), particularly ch 7: A Pudlo and L Gruszczynski, "Regulating e-cigarettes at the EU level".

13 On EU tobacco control policy and the denormalisation of tobacco use, see G Howells, The Tobacco Challenge (Farnham, Ashgate 2011); D Studlar, "Tobacco Control: The End of Europe's Love Affair with Smoking" in S Greer and P Kurzer (eds), European Union Public Health Policy: Regional and Global Trends (Abingdon, Routledge 2013); and A Alemanno, "EU Public Health Law and Policy - Tobacco" in T Hervey et al (eds), Research Handbook on EU Health Law and Policy (Cheltenham, Edward Elgar 2017) ch 14.

14 Commission Recommendation 2014/478, OJ 2014 L 214/38. The Grand Chamber dismissed Belgium's challenge to the validity of this recommendation in Case C-16/16 P Belgium v Commission [2017] ECLI:EU:C:2018:79.
} 
minors or induce them to view gambling as a natural element of their leisure time activities. More specifically, they should ensure that such communications should not be broadcast, displayed or facilitated in media where children are expected to be the main audience. ${ }^{15}$ The absence of any legally binding EU-wide harmonising rules is surprising considering the internal market implications of online gambling, ${ }^{16}$ which are aggravated by the fact that commercial gambling is sustained and promoted by a powerful global industry in ways that not only make it more widespread, but also shape how we think about appropriate policy responses to the health effects of its products. $^{17}$

As far as alcohol and unhealthy food marketing is concerned, the EU may have attempted to protect children from their harmful impacts, but it has consistently failed to do so effectively. This is surprising for many reasons. Firstly, unhealthy diets and alcohol are two of the main risk factors for chronic diseases, and their marketing contributes to increased consumption. As a result, the international community has called for over a decade for wide-ranging restrictions on their marketing, including the regulation of cross-border marketing. Even in the absence of an equivalent to the legally binding FCTC, countless commitments have been made by EU Member States to reduce the harmful impact of alcohol and food marketing on children. ${ }^{18}$ If nutrition and health claims made on food, including alcohol, are regulated at the EU level, ${ }^{19}$ they are only one of many marketing techniques, and their regulation should only constitute a small part in the implementation of these commitments.

Secondly, as the food and alcohol industries are powerful business actors engaging in extensive lobbying against the imposition of marketing restrictions, it seems extremely counterintuitive that they should be entrusted with the design and implementation of policies that they oppose. Real, perceived or potential conflicts of interest must be avoided, or at the very least carefully managed. ${ }^{20}$ However, throughout the years, the EU has put in place governance structures such as the EU Platform for Action on Diet, Physical Activity and Health or the EU Alcohol and Health Forum that allow

\footnotetext{
15 More generally, see MA Carran, Gambling Regulation and Vulnerability (Cheltenham, Edward Elgar 2018).

16 The case law of the CJEU is extensive in this field. See, in particular, Case C-920/19 Summary of the request for a preliminary ruling lodged on 16 December 2019, and the case law referred to therein.

17 H Wardle et al, "Gambling and public health: we need policy action to prevent harm" (2019) 365(11) BMJ 807, who drew an analogy with tobacco, alcohol and unhealthy food, referring to R Moodie et al, "Profits and pandemics: prevention of harmful effects of tobacco, alcohol, and ultra-processed food and drink industries" (2013) 381 The Lancet 670. More recently, see also B Swinburn et al, "The Global Syndemic of Obesity, Undernutrition, and Climate Change: The Lancet Commission Report” (2019) 393 The Lancet 802.

18 They include: WHO Global Strategy to Reduce the Harmful Use of Alcohol (Resolution WHA 63.13); WHO Set of Recommendations on the Marketing of Foods and Non-Alcoholic Beverages to Children (Resolution WHA 63.14); WHO Global Action Plan for the Prevention and Control of NCDs 2013-2020 (Resolution WHA 66.10); Final Report of the WHO Commission on Ending Childhood Obesity (Resolution WHA 69.8).

19 Corrigendum to Regulation 1924/2006 on nutrition and health claims made on foods [2007] OJ L 12/3, whose validity was challenged in Case C-544/10 Deutsches Weintor [2012] ECLI:EU:C:2012:526. On the regulation of EU food claims, see M Friant-Perrot and A Garde, "From BSE to Obesity - EFSA's Growing Role in the EU's Nutrition Policy" in A Alemanno and S Gabbi, Foundations of EU Food Law and Policy: Ten Years of the European Food Safety (Abingdon, Routledge 2014) ch 8. On alcohol more specifically, see O Bartlett and A Garde, "On the Rocks: A Few Sobering Thoughts on the Growing EU Alcohol Problem" in T Hervey et al (eds), Research Handbook on EU Health Law and Policy (Cheltenham, Edward Elgar 2017) ch 15.

20 A Garde, B Jeffery and N Rigby, "Implementing the WHO Recommendations whilst Avoiding Real, Perceived or Potential Conflicts of Interest" (2017) 8(2) European Journal of Risk Regulation 237.
} 
conflicts of interests to flourish, with no reflection on what would constitute appropriate forms of engagement. ${ }^{21}$ It is well documented that industry pledges to promote food "responsibly" to children are riddled with loopholes, ${ }^{22}$ and even though the EU Pledge $^{23}$ has been reviewed over time, it remains inadequate. Public-private partnerships have inherent limits and cannot provide the effective protection that Member States and the EU must grant all children from harmful marketing by virtue of their international human rights obligations. ${ }^{24}$

Thirdly, the EU has missed countless opportunities to effectively reduce the harmful impacts of alcohol and food marketing on children, despite nearly two decades of evidence-based civil society advocacy. The latest amendment of the AVMSD is a resounding failure that has not gone unnoticed. ${ }^{25} \mathrm{~A}$ few improvements aside, its provisions remain far too limited in scope to reduce children's actual exposure to unhealthy food and alcohol marketing. Furthermore, the freedom that the AVMSD grants Member States to adopt stricter standards is circumscribed by the State of Establishment principle, which prevents such standards from applying to audiovisual media service providers established in other territories. ${ }^{26}$ The complaint Sweden initiated in 2011 concerning the broadcasting into Sweden of alcohol advertising by two broadcasters established in the UK illustrates the difficulties. Sweden notified the European Commission, outlining that they wanted to take measures against the broadcasting companies in question. However, in 2018, the Commission responded that Sweden could not derogate from the State of Establishment principle and rejected the claim that the broadcasters had established themselves in the UK in order to circumvent the stricter Swedish alcohol advertising rules. ${ }^{27}$ Isn't it paradoxical that Member States may be significantly better off in the absence of existing EU rules purporting to protect public health?

\footnotetext{
21 O Bartlett and A Garde, "The EU Platform and the EU Forum: New Modes of Governance or a Smokescreen for the Promotion of Conflicts of Interest?" in A Alemanno and A Garde (eds), The Emergence of an EU Lifestyle Policy: The Case of Alcohol, Tobacco and Unhealthy Diets (Cambridge, Cambridge University Press 2015).

22 LL Sharma, SP Teret and KD Brownell, "The food industry and self-regulation: standards to promote success and to avoid public health failures" (2010) 100(2) American Journal of Public Health 240; A Garde, EU Law and Obesity Prevention (Alphen aan den Rijn, Kluwer 2010) ch 5; AB Gilmore, E Savell and J Collin, "Public health, corporations and the New Responsibility Deal: promoting partnerships with vectors of disease?" (2011) 33(1) Journal of Public Health 2; S Galbraith-Emami and T Lobstein, "The impact of initiatives to limit the advertising of food and beverage products to children: a systematic review" (2013) 14(12) Obesity Review 960; C Hawkes and JL Harris, "An analysis of the content of food industry pledges on marketing to children" (2011) 14(8) Public Health and Nutrition 1403; JD Jensen and K Ronit, "The EU pledge for responsible marketing of food and beverages to children: implementation in food companies" (2015) 69(8) European Journal of Clinical Nutrition 896.

$23<$ https://eu-pledge.eu/>.

24 A Grover, "Unhealthy Foods, Non-Communicable Diseases and the Right to Health", A/HRC/26/31, Report of the Special Rapporteur on the right to health, United Nations, 1 April 2014, para 25.

25 For example, the Regional Office for Europe of the WHO noted the shortcomings of EU rules on food marketing in Evaluating the Implementation of the WHO Set of Recommendations on the Marketing of Foods and Non-alcoholic Beverages to Children: Progress, Challenges and Guidance for Next Steps in the WHO European Region (Copenhagen: WHO 2018).

26 O Bartlett and A Garde, "Time to Seize the (Red) Bull by the Horns: The EU's Failure to Protect Children from Alcohol and Unhealthy Food Marketing” (2013) 38(4) European Law Review 498; O Bartlett and A Garde, “The EU's Failure to Support Member States in their Implementation of the WHO Recommendations: How to Ignore the Elephant in the Room?" (2017) 8(2) European Journal of Risk Regulation 251.

27 Commission decision of 31 January 2018 on the incompatibility of the measures notified by Sweden pursuant to Art 4(5) of the AVMSD, C(2018) 532 final.
} 
The extent to which food, alcohol and gambling cross-border marketing is regulated at the regional level is a question of political will, but it also stems from the leadership failure of the EU, who has not used the tools at its disposal to try and convince reluctant Member States of the need for harmonised cross-border marketing restrictions to protect children from harm. As discussed above, the EU itself has contributed for years to the rhetoric that self-regulation and the exchange of best practice promote better health. This flies in the face of existing evidence, and as such does not contribute to the protection of public health, ${ }^{28}$ consumer $^{29}$ and children's rights, ${ }^{30}$ which the EU Treaties and the EU Charter mandate the EU to ensure in the development and implementation of all of its policies. The internal market shall work for the sustainable development of Europe. ${ }^{31}$

The EU should be much bolder in how it regulates harmful cross-border marketing. The development of a new EU Children's Rights Strategy ${ }^{32}$ provides yet another opportunity for the EU to reconcile its rhetoric on children's rights and the harmonising measures required to effectively protect children from such marketing.

\section{The forthcoming EU Children’s Rights Strategy 2021-2024}

The EU has not been insensitive to repeated calls to regulate food and alcohol marketing more effectively. In the last few years, several EU Council Presidencies have specifically considered the impact of unhealthy diets ${ }^{33}$ and alcohol consumption ${ }^{34}$ on children, highlighting the specific contribution of EU cross-border marketing regulation. ${ }^{35}$

\section{Harmful marketing as a major children's rights concern}

The EU has also expressed a growing interest in the use of child rights-based approaches to address harmful marketing. Not only are children's rights increasingly mentioned in high-level policy documents, ${ }^{36}$ but also they feature prominently in the Joint Research Centre report on food and alcohol marketing. ${ }^{37}$ This change in the EU's discourse on

\footnotetext{
28 Arts 9, 114(3) and 168(1) TFEU and Art 35 EU Charter.

29 Arts 12, 114(3) and 169(1) TFEU and Art 38 EU Charter.

30 Art 3(3) TEU and Art 24 EU Charter.

31 Art 3(3) TEU.

$32<$ https://ec.europa.eu/info/law/better-regulation/have-your-say/initiatives/12454-Delivering-for-children-an-EUstrategy-on-the-rights-of-the-child $>$. See, in particular, the feedback received from the European Public Health Alliance and the European Heart Network to the Roadmap published in June.

33 See, eg, Council Conclusions to Contribute towards Halting the Rise in Childhood Overweight and Obesity, OJ 2017 C 205/46 (Maltese Presidency); and Council Conclusions on Healthy Nutrition for Children: The Healthy Future of Europe, OJ 2018 C 232/1 (Bulgarian Presidency).

34 Council Conclusions on Cross-Border Aspects in Alcohol Policy - Tackling the Harmful Use of Alcohol, OJ 2017 C 441/3 (Estonian Presidency).

35 Para 32 of the Bulgarian EU Council Presidency Conclusions (supra, note 33) stresses "with concern that the various approaches to regulation of marketing existing at local, regional or national level may not be as effective as regulation of cross-border marketing for the whole EU, bearing in mind the cross-border dimension of the problem, particularly in the digital media". See also Estonian Council conclusions (supra, note 34).

36 See, in particular, the Maltese and the Bulgarian Council conclusions (supra, note 33).

37 Joint Research Centre, Marketing of Food, Non-Alcoholic, and Alcoholic Beverages: A Toolkit to Support the Development and Update of Codes of Conduct (European Commission 2019).
} 
marketing to children is welcome and reflects the growing consensus in the EU and beyond that unhealthy food environments, ${ }^{38}$ and harmful marketing more specifically, ${ }^{39}$ should be envisaged as major children's rights concerns. In particular, the EU has recognised, at least in relation to unhealthy food, that further progress is required on the implementation of the WHO recommendations on the marketing of foods and non-alcoholic beverages to children, in line with the best interests of the child principle and the EU's public health mainstreaming obligation. ${ }^{40}$

However, references to children's rights are not sufficient in and of themselves to ensure that these rights are effectively upheld. Human rights commitments must translate into practice and contribute to the improvement of children's daily lives. After mandating that "children shall have the right to such protection and care as is necessary for their well-being", ${ }^{41}$ the EU Charter mandates that "in all actions relating to children, whether taken by public authorities or private institutions, the child's best interests must be a primary consideration". ${ }^{42}$ This provision implements Article 3(1) $\mathrm{CRC}$, which has been interpreted extensively by the Committee on the Rights of the Child, requiring that policymakers should prioritise possible solutions that are in the child's best interests. ${ }^{43}$

The obligation to make the best interests of the child a primary consideration becomes crucial when States are engaging in weighing competing priorities. The best interests of the child principle requires that the EU explains how the right to have the best interests of the child considered has been respected in decision-making, including how it has been weighted against other considerations. ${ }^{44}$ Therefore, even if the Committee has stopped short of stating that short-term economic considerations (often invoked against regulation by business actors) should not be given priority over longer-term child development considerations, the requirement to "explain" increases the burden on States to ensure that they move away from mere rhetoric and engage with actual evidence when balancing competing rights and interests, using children's rights impact assessments and children's rights impact evaluations. ${ }^{45}$

\section{What does this mean in practice for the EU?}

The implications of a rights-based approach to the regulation of harmful commercial marketing should lead the EU both to recognise that the approach it has taken to date on the regulation of gambling, alcohol and unhealthy food marketing has failed and

\footnotetext{
38 UNICEF and UN Special Rapporteur on the Right to Food, Protecting Children's Right to a Healthy Food Environment (UNICEF and United Nations Human Rights Council 2019).

39 UNICEF, A Child Rights-Based Approach to Food Marketing: A Guide for Policy Makers (UNICEF 2018).

40 Para 34 of the Bulgarian Council conclusions (supra, note 33).

41 Para 1.

42 Para 2.

43 CRC Committee, General comment No. 15, The Right of the Child to the Enjoyment of the Highest Attainable Standard of Health (Art. 24), CRC/C/GC/15, 17 April 2013.

44 ibid.

45 A Garde and S Byrne, "Combatting obesogenic commercial practices through the implementation of the best interests of the child principle" in A Garde, J Curtis and O De Schutter, Ending Childhood Obesity: A Challenge at the Crossroads of International Economic and Human Rights Law (Cheltenham, Edward Elgar 2020 forthcoming) ch 10.
} 
to reflect on how the successes it has met in relation to tobacco control can be replicated for other commercial determinants of health through the more effective use of its legislative powers under Article 114 TFEU.

Firstly, even though it is most unlikely that the EU will adopt a horizontal instrument addressing the impacts of all forms of harmful marketing on children, the EU should nonetheless acknowledge that its current piecemeal, disjointed approach has proven ineffective and allowed for major gaps in the EU regulatory framework. The harmful impacts of tobacco, alcohol, food and gambling marketing should be primarily envisaged as major public health concerns with significant children's rights implications. Consequently, its regulation should be entrusted to the DirectorateGeneral for Health and Food Safety, rather than other Commission Directorates-General.

Secondly, the EU should seriously reflect on the extent to which codes of conduct have failed to protect children from exposure to unhealthy food marketing and consider adopting EU-wide legally binding provisions to this effect.

Thirdly, the EU should align its regulatory framework with existing evidence and systematically rely on child rights impact assessments and child rights impact evaluations rather than empty industry rhetoric to determine where the child's best interests lie. In particular, it should recognise that all children, including adolescents, are negatively affected by marketing and need protection. It should also acknowledge that the distinction between direct and indirect marketing to children is artificial and should therefore adopt comprehensive restrictions protecting children from actual exposure to harmful cross-border marketing on all programmes and media that they engage with and in all settings where they gather, irrespective of whether these programmes, media and settings are "for", "directed at" or "targeted at" children. 46 More specifically:

- The EU should allow harmful commercial marketing on television only at specifically defined times when children can reasonably be expected not to watch television (eg from 9.00 p.m. to 5.30 a.m. as proposed in the $\mathrm{UK}^{47}$ ).

- The EU should impose equivalent restrictions on all online digital media. Regulating digital marketing admittedly raises acute challenges, not least because large advertising and technology (ad tech) companies tend to operate behind "walled gardens", preventing policymakers from fully understanding their modus operandi. ${ }^{48}$ In the absence of transparency, one could envisage a presumption whereby food, alcohol and gambling marketing is prohibited, except if food, alcohol and gambling companies, together with the ad tech

\footnotetext{
46 ibid. For gambling and alcohol, the argument could be made that the EU should go further and regulate all forms of marketing to adults and children alike, bearing in mind their addictive properties and their contribution to health inequities. However, if political will was insufficient to regulate alcohol and gambling marketing as the EU has done for tobacco, the focus of EU measures should be on children (including adolescents), with a clear provision stating that EU measures do not prevent Member States from adopting further measures, subject to the general free movement Treaty provisions. It is indeed better to recognise the limited scope of EU harmonisation than tie the hands of Member States through the adoption of ineffective common standards.

47 Introducing Further Advertising Restrictions on TV and Online for Products High in Fat, Sugar and Salt (HFSS), 18 March 2019.

48 WHO, Monitoring and Restricting Digital Marketing of Unhealthy Products to Children and Adolescents (Copenhagen, WHO 2019).
} 
companies that they work with, can demonstrate that children below eighteen years of age are not exposed to harmful marketing.

- In a similar vein, the EU should regulate all forms of unhealthy food, alcohol and gambling sponsorship with cross-border effects in such a way that children can attend family events without being exposed to such forms of commercial promotions. In particular, the United Nations Special Rapporteur on the Right to Health has urged governments to "ban the advertising, promotion and sponsorship of all children's sporting events, and other sporting events which could be attended by children, by manufacturers of alcohol, tobacco and unhealthy foods". ${ }^{49}$ Arguably, sports and other forms of sponsorship should only be allowed at adult-only events if children of all ages are to be effectively protected from exposure.

- Finally, recognising the power of packaging as a marketing tool, the EU should prevent the use of marketing techniques appealing to children on packaged goods too. In particular, it should draw inspiration from Chile, where equity brand characters and other popular marketing devices have been banned to protect children from unhealthy food marketing.

\section{Conclusion}

The obstacles will be formidable, but the momentum is growing to protect children from harmful commercial marketing. COVID-19 further increases the urgency of regulating the commercial determinants of health effectively, as the alcohol, food and gambling industries have been shown to "capitalise" on a public health pandemic to increase their profits to the detriment of public health. ${ }^{50}$

It is welcome that the Commission intends to design its Europe's Beating Cancer Plan to cover the entire cycle of the disease, starting from prevention and early diagnosis to treatment and the quality of life of patients and survivors. Even though up to $40 \%$ of cancers may be preventable, only $3 \%$ of health budgets on average are spent on prevention across the EU. ${ }^{51}$ With the current impact of COVID-19 on health in general, and on cancer prevention and care specifically, the Commission has recognised the pressing need to do more, and has proposed $€ 9.4$ billion in EU

\footnotetext{
49 Human Rights Council, "Sport and Healthy Lifestyles and the Right to Health", Report of the Special Rapporteur on the right of everyone to the enjoyment of the highest attainable standard of physical and mental health, UN Doc A/HRC/32/33, 4 April 2016, paras 32 and 33. On sports sponsorship, see A Garde and N Rigby, "Going for Gold Should Responsible Governments Raise the Bar on Sponsorship of the Olympic Games and Other Sporting Events by Food and Beverage Companies?" (2012) 17 Communications Law 42; R Ireland et al, "Commercial Determinants of Health: Advertising of Alcohol and Unhealthy Foods during Sporting Events" (2019) 97 Bulletin of the World Health Organization 290.

50 See, in particular, the mapping of corporate responses to the pandemic undertaken by the NCD Alliance and the SPECTRUM research consortium: <https://ncdalliance.org/why-ncds/covid-19/map-unhealthy-industry-responses > .

$51<$ https://ec.europa.eu/info/law/better-regulation/have-your-say/initiatives/12154-Europe-s-Beating-CancerPlan>.
} 
funding for its EU4Health programme, ${ }^{52}$ hoping to significantly increase its support for cancer prevention and care.

The EU has missed many opportunities to address harmful commercial marketing; COVID-19, coupled with the development of a new EU Children's Rights Strategy, highlights the imperative for the EU to rethink its chronic diseases prevention strategy, not least by putting the best interests of the child at the heart of EU marketing regulation.

52 Proposal for a Regulation on the establishment of a Programme for the Union's action in the field of health for the period 2021-2027 ("EU4Health programme"), COM(2020) 405 final. 